\title{
Obesity and Diabetes in Vulnerable Populations: Reflection on Proximal and Distal Causes
}

Lucy M. Candib, MD

Department of Family Medicine and Community Health, University of Massachusetts Medical School and Family Health Center of Worcester, Worcester, Mass
Conflicts of interest: none reported

\section{CORRESPONDING AUTHOR}

Lucy M. Candib, MD

Family Health Center of Worcester

26 Queen St.

Worcester, MA 01610

lcandib@massmed.org

\begin{abstract}
Around the world obesity and diabetes are climbing to epidemic proportion, even in countries previously characterized by scarcity. Likewise, people from low-income and minority communities, as well as immigrants from the developing world, increasingly visit physicians in North America with obesity, metabolic syndrome, or diabetes. Explanations limited to lifestyle factors such as diet and exercise are inadequate to explain the universality of what can be called a syndemic, a complex and widespread phenomenon in population health produced by multiple reinforcing conditions. Underlying the problem are complex factors-genetic, physiological, psychological, familial, social, economic, and political-coalescing to overdetermine these conditions. These interacting factors include events occurring during fetal life, maternal physiology and life context, the thrifty genotype, the nutritional transition, health impact of urbanization and immigration, social attributions and cultural perceptions of increased weight, and changes in food costs and availability resulting from globalization. Better appreciation of the complexity of causation underlying the worldwide epidemic of obesity and diabetes can refocus the work of clinicians and researchers to work at multiple levels to address prevention and treatment for these conditions among vulnerable populations.
\end{abstract}

Ann Fam Med 2007;5:547-556. DOI: 10.1370/afm.754.

\section{INTRODUCTION}

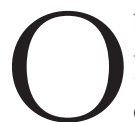

besity, and its coconspirator, diabetes, increasingly dominate health problems for immigrants, low-income populations, and communities of color. North American physicians who provide primary health care to low-income communities and immigrant populations from the developing world confront such vulnerable patients every day. From Asia, South Asia, the Middle East, Africa, Latin America, and the Caribbean and from indigenous populations, patients seek consultation for a variety of symptoms. Often the initial investigation of the patient, who may be seriously overweight, reveals previously undiagnosed hypertension, diabetes, metabolic syndrome, or dyslipidemia. These conditions appear to relate to personal behaviors based on lifestyle decisions. When these vulnerable patients-be they black, Hispanic, Native American, poor, or immigrant-fail to change their diet or lose weight or exercise, and take their medications erratically owing to cost or misunderstanding or sheer disbelief in the need for daily medication, physicians may attribute the problem to failure of personal responsibility. Epidemiologic studies often focus on individual characteristics and behaviors to explain these problems rather than examine the multiple forces at work. ${ }^{1}$ Nevertheless, the epidemic increase in obesity and diabetes around the world suggests that factors far beyond individual behaviors must be at work to explain this recent global process. In this essay, I describe some 
of the emerging understandings about the interacting causes of this worldwide phenomenon with a particular focus on immigrants and members of low-income communities and communities of color within North America.

\section{The Need for Systems Thinking}

In the United States and other developed nations, diabetes and obesity are markers for inequalities in health. Although these infirmities affect all segments of the population, minority populations, low-income communities, and immigrants (especially as time passes since arrival) are disproportionately afflicted. ${ }^{2-5}$ Around the world emerging nations likewise face this pandemic, but in those cases, the social inequality stands in relation to global economic policy. Internationally it may not be the very poorest populations who face diabetes and obesity, but rather it may be those with some access to the cheapest foodstuffs. The merger of many interacting forces conjoined in creating this global phenomenon calls for explanatory models and ways of thinking that go beyond traditional singular notions of causality. Within the field of social epidemiology, "ecosocial and other emerging multi-level frameworks seek to integrate social and biological reasoning and a dynamic, historical and ecological perspective to develop new insights into determinants of population distributions of disease and social inequalities in health."

To introduce this approach into family medicine, I will describe several of these determinants of the obesity/diabetes epidemic, ranging from the genetic, cellular, biologic, and psychological levels to the social, historical, economic, and political. I will suggest that systems thinking may provide a way to consider such an enormous problem, marked by com- plexity at every level. Finally, I will offer some areas of action for family medicine in the realms of research, collaboration, and advocacy.

\section{OVERDETERMINATION OF OBESITY, DIABETES, AND RISK OF VASCULAR DISEASE}

Although North Americans are familiar with the obesity epidemic, they may be less aware of the truly global extent of the problem. Around the world, especially in developing nations, a constellation of factors conspire to guarantee that obesity, with the high likelihood of ensuing diabetes, will afflict entire populations (Figure 1). The terms used to describe these factors may be unfamiliar to practicing clinicians but are commonly understood among public health experts in nutrition. Recent editorials in major medical journals have begun to bring some of these factors to wider attention. ${ }^{7-9}$ These factors include the following:

- Fetal and maternal explanations

- The thrifty genotype

- The nutritional transition

- The health impact of urbanization and immigration

- Social attributions and cultural perceptions of increased weight

- The impact of globalization on nutrition

\section{Fetal and Maternal Explanations}

Recent research suggests that an adverse intrauterine environment leading to low birth weight is linked with the later development of obesity and the metabolic syndrome. ${ }^{10-12}$ This explanation is sometimes called the thrifty phenotype: the calorically deprived fetus and later child responds by hoarding calories as an environmental response. Put another way, the

Figure 1. Pathways to obesity and diabetes.

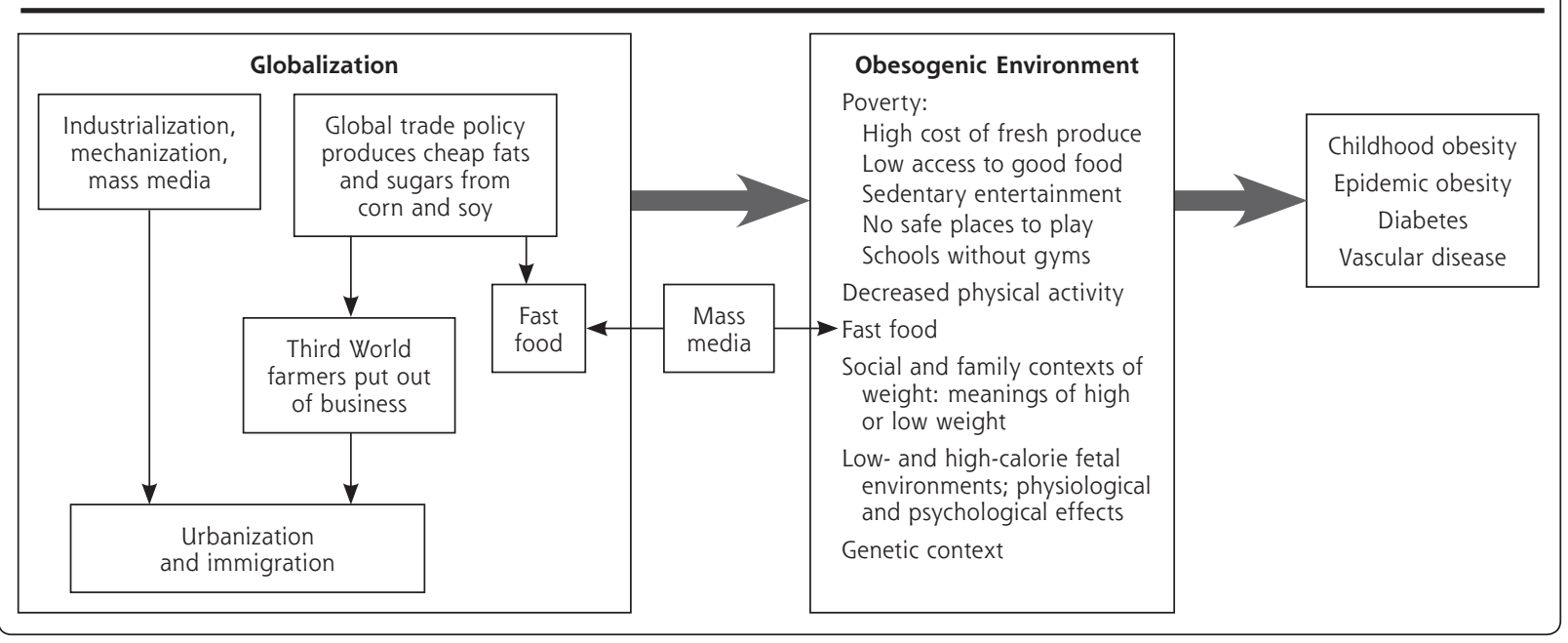


"fetal origins of disease" hypothesis postulates that early (intrauterine or early postnatal) undernutrition causes an irreversible differentiation of metabolic systems, which may, in turn, increase the risks of certain chronic diseases in adulthood." ${ }^{\text {(p1515) }}$ In one scenario, the fetus permanently switches on genes to maximize energy conservation, causing excess accumulation of energy (and therefore body fat) when the individual gets unrestricted calories later. Physiologically, the hypothesized chain of events is that fetal malnutrition leads to relative tissue resistance to insulin, low birth weight, childhood fat deposition, later childhood and early adult insulin resistance, and ultimately adult diabetes. Another hypothesis derived form animal models is that the maternal organism programs the biologically plastic fetal system to prepare for the caloric environment that it will face. When there is a mismatch between the preparation for scarcity during fetal life with the relative abundance of calories later, the result is a predisposition for caloric hoarding, childhood fat deposition, and so on. ${ }^{13-16}$ (Maternal smoking, strongly associated with fetal deprivation in the form of intrauterine growth retardation, also contributes to the mismatch. Teen offspring of women who smoked during pregnancy are more likely to be overweight or obese than offspring of women who had never smoked or had quit smoking. ${ }^{17}$ ) Thus the intrauterine growth retardation and low birth weight common to babies in developing countries, (but also not infrequent in the United States), where their mothers do not obtain adequate calories, may establish populations of adults susceptible to obesity and the associated conditions.

Supporting this idea of the thrifty phenotype are focused animal studies ${ }^{13,18}$ (not addressed here) and multiple epidemiologic studies. For instance, Dutch investigators found that women who were pregnant during a specific period of severe caloric restriction in the Netherlands during World War II were more at risk to give birth to low birth weight infants who in adulthood had increased risk for conditions leading to diabetes and vascular disease. ${ }^{19,20}$ Likewise, Finnish data of children born between 1934 and 1944 show the later impact of low birth weight. The more that low birth weight babies who were thin up until age 2 years increased their weight in relation to height between ages 2 and 11 years, (ie, their body mass index began to cross the growth curves), the more likely they were to develop insulin resistance and coronary disease as adults. ${ }^{21}$

This dynamic has emerged whenever researchers have followed low birth weight infants in developing countries. These regions are the homes of origin of many immigrants to North America, yet their experience of poor nutrition during the fetal period may be unknown or opaque to the clinicians who encounter them as adults. For instance, in India-the second leading country of immigrants to the United States in $2005^{22}$ - the accelerated increase of the body mass index during childhood (early adiposity rebound) of low birth weight infants correlates with later impaired glucose tolerance and frank diabetes by the age of 26 years. Although such children are not necessarily obese by Western standards, they have more truncal fat and their risk of diabetes is still higher. ${ }^{23}$ In Guatemala, severely stunted babies are more likely to become adults with central obesity, especially if their mothers migrated to urban centers. ${ }^{24}$ In Mexico, when documented early malnutrition among boys was followed by the later development of abdominal fat, insulin resistance was also more likely. ${ }^{25}$ Likewise, the emerging high rates of glucose intolerance, diabetes, and hypertension in Cambodia may relate to the long periods of deprivation suffered by the Cambodian people during the last 50 years. ${ }^{26}$

Maternal biological responses, in addition to fetal reactions, may also foster later problems for both mother and child. In some instances, maternal insulin resistance during pregnancy may protect against fetal malnutrition by preferentially driving available calories toward the fetus; such a tendency obviously portends a later risk of diabetes for the mother. ${ }^{12}$ In settings of excess calories during pregnancy, so-called maternal overnutrition, typical of urban settings of the late 20th century, maternal insulin resistance has been associated with high birth weight, which itself correlates with later obesity and insulin resistance. This description,

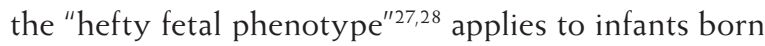
to the growing number of obese women who have insulin resistance but not yet gestational diabetes in pregnancy. Studies from various regions confirm an association between maternal body mass index, birth weight, and later adolescent and adult obesity. ${ }^{29-31}$ With two thirds of adult women in the United States overweight, and at least one third of whom are obese (with even higher rates among low-income and women of color), insulin resistance in pregnancy is becoming commonplace. Thus, distinct from any inherited tendency toward diabetes, impaired fetal nutrition itself, mediated through the mother's body, generates tendencies at both ends of the infant weight curve toward obesity and diabetes in adulthood.

The resulting epidemic of diabetes in the next generation of North Americans, children of both immigrants and native-born, looms large. Social and psychological maternal factors, as well as the biological, contribute to their offspring's risk for obesity and diabetes. Mothers who have small thin babies will want to fatten them. Unfortunately, the resulting rapid weight gain for children in infancy and in early childhood is 
associated with later obesity. ${ }^{32-34}$ Mothers, too, may engage in excess eating at those times when they have more access to food, and in the United States food insecurity is associated with overweight, especially for women. ${ }^{35,36}$ The experience of food insecurity and scarcity is likewise a strong stimulus to push calories into children when food becomes available. ${ }^{37}$ Thus it is not surprising that low socioeconomic status in childhood would be a predictor of obesity for African American women as adults. ${ }^{38}$ So not only the prenatal environment but also the later socioemotional context in which the perhaps small-for-age child grows and eats-especially if food is not reliably available_-promotes the development of later obesity and diabetes.

\section{Thrifty Genotype}

This hypothesis proposes that the ability to conserve calories by laying down abdominal fat offers a genetic advantage for selection of this genotype during periods of food scarcity in human history. ${ }^{39,40}$ All humans are likely to have genetically determined mechanisms to survive caloric restriction, but some people may have thriftier genotypes than others, resulting in a higher likelihood of obesity when they are faced with higher caloric loads. ${ }^{41} \mathrm{With}$ increases in caloric intake and decreases in physical activity brought about by economic and social changes, the genetically driven tendency toward central fat deposition becomes a health hazard. Such visceral fat is directly related to the development of insulin resistance and eventually diabetes. This hypothesis has been criticized for its potential to confuse genes with race and its application of biological determinism in the explanation of diabetes without addressing the social determinants of disease $\mathrm{e}^{42}$; however, unique ethnic patterns of abdominal fat deposition resulting from a variety of genetic mutations are demonstrable. ${ }^{12}$ Compared with white Europeans, ethnic groups from developing countriesas well as native Americans, native Canadians, Maori, Asian Pacific islanders, and many other native populations $^{43-45}$ — are more vulnerable to the development of diabetes, possibly because of genetic selection for those who could withstand starvation. Why the rate of diabetes among Europeans is lower despite famines in European history is subject to speculation: perhaps because of the differing patterns of famine, differing ways regions addressed food scarcity, or out-migration of those most at risk for diabetes. ${ }^{46}$

\section{Nutritional Transition}

Fetal and genetic explanations do not fully explain why obesity and its consequences have burgeoned so rapidly in the last few decades. Clearly, changes in the environment interact with the other factors in a lethal combination: "The genetic background loads the gun, but the environment pulls the trigger." ${ }^{\prime \prime 7}$ Even in the developing world, obesity, diabetes, and vascular disease are replacing undernutrition and infectious disease as the main health risks. Whereas previously poverty was linked with low calorie intake, this pattern has shifted with the wide accessibility of cheap fats and the rapid increase in the consumption of high-fructose corn syrup around the world. ${ }^{47,48}$

The change from a pattern of low calories and low fat in resource-poor settings to higher calories and high fat is termed the nutritional transition. For instance, in Brazil the lowest income quartile of women contains the highest prevalence of obesity as well as of underweight women. ${ }^{8}$ In Brazil and India, higher weight and therefore higher risk of diabetes are more prevalent among the lower income groups. Consequently, especially among the poor, rates of cardiovascular disease are already rising precipitously in India, where the projected number of people with diabetes will approach 60 million by $2025 .^{7}$ In many settings in the United States and abroad, poor maternal nutrition and excess calories coexist in the same environment, constituting the dual burden household. In Morocco, where underweight and stunting among children are prevalent, obesity among children and adults, especially women, is also on the rise. ${ }^{49}$ "Cheap energy-dense, nutrientpoor foods may adversely affect the growth of the child but may provide sufficient calories for the adult to gain excess weight." ${ }^{\text {(p1515) }}$

\section{Health Impact of Urbanization and Immigration}

Globally, people migrate from rural areas to the cities in search of work, more income, and a better life. Practically speaking, they walk less, ride more, watch more television, and eat a diet higher in fat and sugars when they live in the city. They have less access to homegrown and local vegetables and are more likely to eat fast foods, as well as fried foods and sugary drinks widely accessible from vendors on the street. Thus obesity and its sequelae are increasing ominously in cities in the developing world ${ }^{8,50}$ Recognizing the enormity of this problem in the face of increasing urbanization, the World Health Organization (WHO) issued in a report recommending that fat consumption be limited to $20 \%$ to $25 \%$ of caloric intake. ${ }^{51}$ Inner-city dwellers in North America face similar issues: unavailable or expensive fresh fruits and vegetables, less access to safe settings for exercise, reliance on television for entertainment of adults and children, proliferation of fastfood vendors, and economic pressures limiting time for family meals at home. Children attend urban schools that rely on high fat-high carbohydrate foodstuffs in 
lunch programs at the same time that budget cuts often reduce or eliminate gym. Although city dwellers living in mixed-use neighborhoods may walk more than suburbanites, low-income families in the inner-city areas truly live in an obesogenic environment. ${ }^{52,53}$

Urbanization and migration are worldwide responses to poverty and lack of employment and have similar impacts on people's weight. For instance, as time passes after migration, obesity among the arrivals becomes increasingly likely. ${ }^{4,54,55}$ The prevalence of diabetes increases about 20 years after immigration in multiple ethnic groups entering more high-calorie, lowactivity environments. ${ }^{46}$ The children of immigrants may fare even worse-they appear less likely to choose a traditional diet that historically might have contained an array of nutrients (eg, rice and beans lose out to French fries). For example, in the United Kingdom, second-generation offspring of immigrants appeared to adopt British dietary patterns, increasing their fat intake and reducing their consumption of vegetables, fruit and legumes compared with first-generation immigrants. ${ }^{56}$ In the United States, Asian American and Hispanic American adolescents are more than twice as likely to be obese as the first-generation immigrants from their countries of origin. ${ }^{50}$ Thus the children of immigrants may be at even higher risk of obesity and diabetes than their parents.

\section{Social Attributions and Cultural Perceptions of Increased Weight}

Culture shapes people's view of weight. In many cultures to be big connotes power, wealth, health, and higher social standing. ${ }^{57}$ "Positive valuations of corpulence" are common outside industrialized societies. ${ }^{58}$ Where scarcity and hunger are still realities, a fat baby is a healthy baby, and a skinny adult or one who is losing weight, is thought likely to die, often from a stigmatized disease like tuberculosis or acquired immunodeficiency syndrome. Even though educated adults with stable food supplies may be aware of modern concerns about obesity, the image of the big, strong, powerful, and healthy adult lingers in the collective imagination. In such cultures, losing weight is contrary to the social construct of health. Moreover, extra weight may be seen as attractive or sexually appealing. ${ }^{59}$ In other words, cultures, with all their biological and historical experience, shape how their members consider weight. ${ }^{58}$ These beliefs translate into practices affecting body weight patterns. For instance, in South Africa, a study of more than 1,000 women from urban and rural sites showed a significant positive association between household income and obesity. ${ }^{60}$ Women with higher incomes and lower physical activity were at the greatest risk of increased body mass index, suggesting that, for now, in this region obesity and diabetes will track with income.

Among many people of color in the United States, perceptions and attitudes about obesity can also be at variance with the national preoccupation with thinness African American and Hispanic adults are more likely than white adults to perceive their current overweight status as closer to an ideal body size, and African Americans in general are more likely to perceive obesity as acceptable, desirable, or sexually attractive. ${ }^{61-65}$ Moreover, some of the factors maintaining obesity may have strong cultural determinants related to the role of food. ${ }^{66}$ Although not universal, the positive perceptions of excess weight persist despite the known connection between obesity and the very real health threats of diabetes and vascular disease.

From other viewpoints, some scholars identify the preoccupation with body size as a particularly Western phenomenon, ${ }^{58}$ and others speculate that obesity may not be the top health priority for the black communities. ${ }^{67}$ But such arguments do not address the accelerating accumulation of weight in the most vulnerable populations, particularly in the last 25 years. Regardless of whether an observer thinks that naming large body size as obesity is medicalization, the interaction of those pounds with diabetes, cardiovascular disease, and arthritis is already taking its toll on the health outcomes for Hispanic and African Americans.

\section{Impact of Globalization on Nutrition}

International economic forces interact to the detriment of healthful nutrition. Examples abound: Mexican corn farmers are driven out of the market for corn and into the stream of immigrants at risk for obesity because of such economic policies as the US government's price supports to huge conglomerate corn farms. ${ }^{68}$ The resulting low cost of high-fructose corn syrup makes the calories from sweetened beverages extremely cheap: $\$ 1$ will buy 875 calories of soda. ${ }^{69}$ Global outsourcing has pushed people into sedentary temporary jobs (such as call centers) with work patterns associated with increased fast-food consumption. ${ }^{70}$ Patterns of food preference are also in flux owing to the success of multinational fast-food vendors and changes in the availability of fats and sugars in developing countries. ${ }^{71-73}$

Health authorities are familiar with the dangers of fast fatty and sugary foods, but action is difficult. Although in January 2004 WHO recommended tighter regulation of food advertising aimed at children and other strategies aimed at limiting junk food and soft drink consumption internationally, ${ }_{1}{ }^{74}$ the United States and other sugar-producing countries opposed the release of the report. ${ }^{75,76}$ Not surprisingly, any serious attempt to limit or channel global food marketing will face enormous political opposition from forces 
supported by multinational corporations. ${ }^{73,77}$ The result: global economic forces (ie, world trade policies favoring US corn production, international marketing of fast food, changes in physical activity in work, market-based changes in the availability of domestic products, media promotion of empty calories to children, etc) work synergistically together to produce the same effects-widespread obesity, diabetes, and heart disease in the developing world.

\section{IMPLICATIONS}

These complex and interlocking forces are daunting. Some factors, such as the thrifty genotype and a history of fetal malnutrition, cannot be changed; and others, such as urbanization, pressures around immigration, and cultural values around weight, are beyond the immediate reach of doctors and patients and their health care institutions. Some, like food availability and pressures on urbanization and migration, might potentially be amenable to changes in political and economic policies in specific countries; however, the multinational corporations are certain to oppose policies that will work against their interests. Change would need to be at many levels, from many sectors, working synergistically for healthier options, energized by collective will, and informed by excellent information.

In the United States, action at the federal level is already in motion. The Centers for Disease Control and Prevention (CDC) have been documenting for years the impact of overweight on chronic disease and the association of chronic diseases with low-income status. Now, the Federal Bureau of Primary Care and the Institute for Healthcare Improvement (IHI) are engaging community health centers, already committed to the care of the underserved, to adopt the Wagner Chronic Care Model for chronic diseases. ${ }^{78}$ (see http://www.healthdisparities.net/hdc/html/home.aspx.) The resulting Health Disparities Collaboratives-initially focused on asthma, diabetes, heart disease, and depression-have fostered improvements in teamwork, development of data systems (registries), adherence to standards of care, design of clinical systems, support for decision making, and encouragement of patients' taking charge of their illnesses. The chronic disease collaboratives can make linkages with community resources to promote health education and lifestyle changes in diet and exercise. Childhood obesity is already a target for this model. ${ }^{79}$ Training patients in adoption of self-management strategies, a prime target of the collaborative, is moving forward ${ }^{80}$ Community health centers have improved the processes of care although definite proof of improved disease outcomes is still lacking. ${ }^{81}$ Even though changes in health care cannot address all the social and economic factors elaborated above, broad changes in the health care system, as IHI proposes, are initial steps in working for change (see http://www.ihi.org/ihi.).

How we think about these problems has to change as well. Increasingly public health experts are encouraging clinicians and others concerned about obesity and diabetes to consider a more systemic way of thinking about the enormity of the problem. ${ }^{82}$ Championing such change, the CDC Syndemics Project, proposes that this phenomenon be addressed as a syndemic (a complex and widespread phenomenon in population health produced by multiple reinforcing condition). ${ }^{83,84}$ The term syndemic:

... places the responsibility for affliction squarely within the public arena. It acknowledges relationships and signals a commitment to studying population health as a fragile, dynamic state requiring continual effort to maintain and one that is imperiled when social and physical forces operate in harmful ways. ${ }^{85}$

A syndemic orientation sees "dynamic feedback among afflictions, living conditions, and public strength." ${ }^{183}$ Moving away from disease silos, specialty focus, single-issue organizations, and competition among interest groups for resources, these analysts of obesity and diabetes opt for an activated public health initiative that draws on the energy of all these forces to create change. Indeed, a syndemic approach argues that the same energy that conspires toward the harmful outcome can be harnessed, Jujitsu-style, on behalf of promoting healthful change.

Working for change requires an understanding of what is happening and where it is going. Dynamic modeling is a method to project the extent of a problem going forward in time and to demonstrate the potential impact of single or multiple interventions (Figure 2). ${ }^{84,85}$ These images show graphically that enhanced clinical management of diabetes, as well as recognition and treatment of prediabetes, will have little effect on the magnitude of the epidemic and minimal reduction in deaths secondary to complications of diabetes. The strategy with the most powerful long-term effect in curtailing the escalation is reduction in the prevalence of obesity. Such modeling of complex public health systems incorporates environmental issues, resources, healthy and risky behaviors, delivery systems, and feedback from various interventions; the projections carry the potential to influence policy for the better. ${ }^{86}$

\section{A CALL FOR ACTION}

What does all this have to do with the individual clinician and patient? Clinicians, by definition, work within 


\section{Figure 2. Model output for 3 intervention scenarios compared with the baseline scenario for diabetes prevalence (a) and complication-related deaths (b).}
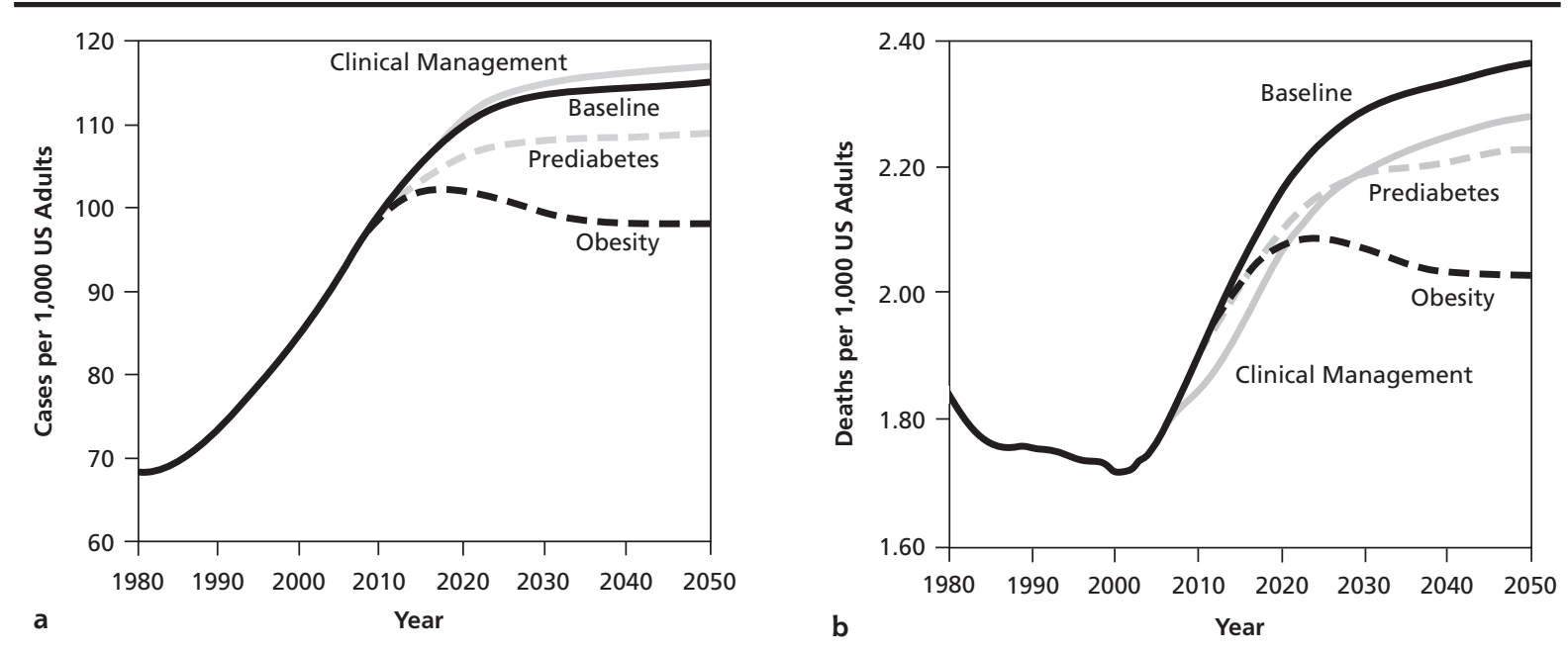

From: Jones AP, Homer JB, Murphy DL, Essien JD, Milstein B, Seville DA. Understanding diabetes population dynamics through simulation modeling and experimentation. Am J Public Health. 2006;96(3):488-494. Reprinted with permission from the American Public Health Association.

the health care system, and can join quality improvement efforts by adopting the chronic care model. This model relies on clinicians and the systems they work in to better address chronic diseases and on patients to undertake management of their illnesses. As the dynamic modeling suggests, however, excellent clinical care will not be enough to change the outcome down the road in 2050. Clinicians need to be involved in change at a broader level.

Clinicians will have to get out of the office, and health care institutions will have to reach out through community collaborations. Economic and social factors may limit patients' abilities to make changes in diet and exercise without a prior intervention at the community level. Clinicians might consider what concrete steps they might take to become involved in local efforts that would make a difference. For instance, health centers can make linkages with local fitness centers to make safe access to exercise more available to patients. ${ }^{87}$ Clinicians in the inner city can open conversations within community groups and leaders about how to support the location of supermarkets in inner-city locations, as the Food Trust did in Philadelphia (see http://www.thefoodtrust. org/php/programs/super.market.campaign.php). Clinicians can engage with patients around the community organizations that matter to them: churches, neighborhood associations, radio stations, etc. In these settings clinicians can take their message out of the office and into the community about what is a good weight, what are healthy foods, the need for increased physical activity, and, for immigrants, how work and activity are different in the new land. Ethnic group associations can promote group education in comfortable settings and suitable language to raise awareness among immigrant families about the health concerns facing them and their children. ${ }^{88}$

Community-based nutritional health and activity interventions have the potential to make a modest public health impact. ${ }^{89,90}$ Many different kinds of communities have had success in fostering community gardens, opening farmers' markets, increasing children's exercise through walk-to-school programs, promoting safe bike and walking paths, and altering the foods available in school lunches and snack machines. ${ }^{73}$ At the larger political level, consumers and professionals can become involved in national efforts to reduce advertising of foods to children, especially on television, putting taxes on junk foods with revenue to support availability of fresh fruits and vegetables, improving the nutritional quality of foods aimed at children, pushing for a code of conduct for the food industry, ${ }^{73,77}$ or getting involved in politics around the US farm policy. ${ }^{68}$ Taking an active part in working for change in nutrition is likely to work against clinicians' sense of helplessness in the face of the pandemics of obesity and diabetes. At the academic level, clinicians can become involved with the CDC Diabetes Prevention Project, joining forces with others who understand the multifactorial nature of the problems and the necessary solutions.

Primary care researchers as well can play a role. Many questions beg for answers:

- How can we foster healthy eating and activity levels without reinforcing the culture of distorted thinness and its potential for anorexia? 
- How can we communicate the urgency of action on healthy activity and eating without further marginalizing and stigmatizing the people who are already overweight and obese?

- What is the best way to engage members of various ethnic groups to take up this challenge?

- Given the long-term ineffectiveness of current individual treatment adult and child obesity, what interventions might work using the chronic care model? Group visits? Multiple family group visits?

- Does role modeling by physicians and other health care workers have any effect on the uptake of healthy behaviors by patients?

Exploring the answers to these and so many more questions needing answers will require qualitative skills and an interest in narrative to gain patients' perspectives. Because these investigations involve vulnerable populations, a participatory research strategy would be the ideal approach.

Practitioners increasingly confront vulnerable patients with obesity, metabolic syndrome, and diabetes, and will soon have to address the huge resultant burden of vascular disease. Although the clinician faces each patient as an individual, or at best, as part of a family, the problems underlying the patient's health risks are not primarily those of individual responsibility, but rather the results of complex factors at work at multiple levels from the cellular to the global. Applying the concept of syndemics will enable the clinician to situate the health problems of vulnerable patients within their genetic, socioeconomic, and migration histories played out in the arena of worldwide economic forces. Whereas individual patients will still require one-on-one and familial interventions, the application of the community linkage aspect of the chronic care model holds the potential for joining with patients and their families to make a difference. Although this work is an uphill battle against prevailing political forces, new tools emerging from syndemic thinking, such as dynamic modeling, point toward more-effective strategies of prevention. Growing collaborations among researchers and clinicians who understand the need for interventions at multiple points can energize those who are committed to reshaping health care and laying the groundwork for lasting prevention of disease among families from vulnerable communities.

To read or post commentaries in response to this article, see it online at http://www.annfammed.org/cgi/content/full/5/6/547.

Key words: Obesity; diabetes; poverty; emigration and immigration; minority groups; nutrition; globalization; syndemics; public health practice

Submitted May 8, 2007; submitted, revised, July 17, 2007; accepted July 17, 2007.

\section{References}

1. Inhorn MC, Whittle KL. Feminism meets the "new" epidemiologies: toward an appraisal of antifeminist biases in epidemiological research on women's health. Soc Sci Med. 2001;53(5):553-567.

2. Kumanyika SK. Special issues regarding obesity in minority populations. Ann Intern Med. 1993;119(7 Pt 2):650-654.

3. Centers for Disease Control and Prevention. Racial/ethnic and socioeconomic disparities in multiple risk factors for heart disease and stroke. United States, 2003. MMWR Morb Mortal Wkly Rep. 2005;54(5):113-117.

4. Kaplan MS, Huguet N, Newsom JT, McFarland BH. The association between length of residence and obesity among Hispanic immigrants. Am J Prev Med. 2004;27(4):323-326.

5. Lauderdale DS, Rathouz PJ. Body mass index in a US national sample of Asian Americans: effects of nativity, years since immigration and socioeconomic status. Int J Obes Relat Metab Disord. 2000;24(9):1188-1194.

6 . Krieger N. Theories for social epidemiology in the 21st century: an ecosocial perspective. Int J Epidemiol. 2001;30(4):668-677.

7. Rastogi T, Vaz M, Spiegelman D, et al. Physical activity and risk of coronary heart disease in India. Int J Epidemiol. 2004;33(4):759-767.

8. Caballero B. A Nutrition paradox: underweight and obesity in developing countries. N Engl J Med. 2005;352(15):1514-1516.

9. Hossain P, Kawar B, El Nahas M. Obesity and diabetes in the developing world: a growing challenge. $N$ Engl J Med. 2007;356(3):213-215

10. Levitt NS, Lambert EV. The foetal origins of the metabolic syndrome: a South African perspective. Cardiovasc J S Afr. 2002;13(4):179-180.

11. Ozanne SE, Fernandez-Twinn D, Hales CN. Fetal growth and adult diseases. Semin Perinatol. 2004;28(1):81-87.

12. Yajnik CS. Early life origins of insulin resistance and type 2 diabetes in India and other Asian countries. J Nutr. 2004;134(1):205-210.

13. Gluckman PD, Hanson MA, Beedle AS. Early life events and their consequences for later disease: a life history and evolutionary perspective. Am J Hum Biol. 2007;19(1):1-19.

14. Gluckman PD, Hanson MA. The consequences of being born small: an adaptive perspective. Horm Res. 2006;65(Suppl 3):5-14.

15. Gluckman PD, Hanson MA. Evolution, development and timing of puberty. Trends Endocrinol Metab. 2006;17(1):7-12.

16. Gluckman PD, Hanson MA, Spencer HG, Bateson P. Environmental influences during development and their later consequences for health and disease: implications for the interpretation of empirical studies. Proceedings /The Royal Society/ Biological Sciences. 2005;272:671-677

17. Al Mamun A, Lawlor DA, Alati R, O'Callaghan MJ, Williams GM, Najman JM. Does maternal smoking during pregnancy have a direct effect on future offspring obesity? evidence from a prospective birth cohort study. Am J Epidemiol. 2006;164(4):317-325.

18. Moore V, Davies M. Nutrition before birth, programming and the perpetuation of social inequalities in health. Asia Pac J Clin Nutr. 2002;11(Suppl 3):S529-S536.

19. Roseboom TJ, van der Meulen JH, Osmond C, Barker DJ, Ravelli AC, Bleker OP. Plasma lipid profiles in adults after prenatal exposure to the Dutch famine. Am J Clin Nutr. 2000;72(5):1101-1106.

20. Roseboom TJ, van der Meulen JH, Ravelli AC, Osmond C, Barker DJ, Bleker OP. Effects of prenatal exposure to the Dutch famine on adult disease in later life: an overview. Mol Cell Endocrinol. 2001;185(1-2):93-98.

21. Barker DJ, Osmond C, Forsen TJ, Kajantie E, Eriksson JG. Trajectories of growth among children who have coronary events as adults. N Engl J Med. 2005;353(17):1802-1809. 
22. Migration Policy Institute. Legal Immigration to United States Increased Substantially in FY 2005. October, 2006; No 13. http:// www.migrationpolicy.org/pubs/FS13_immigration_US_2006.pdf. Accessed July 15, 2007.

23. Bhargava SK. Relation of serial changes in childhood body-mass index to impaired glucose tolerance in young adulthood. $N$ Engl J Med. 2004;350(9):865-875.

24. Schroeder DG, Martorell R, Flores R. Infant and child growth and fatness and fat distribution in Guatemalan adults. Am J Epidemiol. 1999;149(2):177-185.

25. Boule NG, Kenny GP, Haddad E, Wells GA, Sigal RJ. Meta-analysis of the effect of structured exercise training on cardiorespiratory fitness in type 2 diabetes mellitus. Diabetologia. 2003;46(8):1071-1081.

26. de-Graft Aikins A. Healer shopping in Africa: new evidence from rural-urban qualitative study of Ghanaian diabetes experiences. BMJ. 2005;331(7519):737.

27. Nanan DJ. The obesity pandemic: implications for Pakistan. JPMA J Pak Med Assoc. 2002;52(8):342-346.

28. Dyck RF, Klomp H, Tan L. From "thrifty genotype" to "hefty fetal phenotype": the relationship between high birthweight and diabetes in Saskatchewan Registered Indians. Canadian Journal of Public Health. Revue Canadienne de Sante Publique. 2001;92(5):340-344.

29. Hart CL, Hole DJ, Lawlor DA, Davey Smith G. How many cases of type 2 diabetes mellitus are due to being overweight in middle age? Evidence from the Midspan prospective cohort studies using mention of diabetes mellitus on hospital discharge or death records. Diabet Med. 2007;24(1):73-80.

30. Gillman MW, Rifas-Shiman S, Berkey CS, Field AE, Colditz GA. Maternal gestational diabetes, birth weight, and adolescent obesity. Pediatrics. 2003;111(3):e221-e226.

31. Lawlor DA, Davey Smith G, Ebrahim S. Life course influences on insulin resistance: findings from the British Women's Heart and Health Study. Diabetes Care. 2003;26(1):97-103.

32. Monteiro POA, Victora CG. Rapid growth in infancy and childhood and obesity in later life: a systematic review. Obes Rev. 2005;6(2):143-154

33. Dennison BA, Edmunds LS, Stratton HH, Pruzek RM. Rapid infant weight gain predicts childhood overweight. Obes Res. 2006;14(3):491-499.

34. Terry MB, Wei Y, Esserman D. Maternal, birth, and early-life influences on adult body size in women. Am J Epidemiol. 2007;166(1):5-13.

35. Townsend MS, Peerson J, Love B, Achterberg C, Murphy SP. Food insecurity is positively related to overweight in women. J Nutr. 2001;131(6):1738-1745

36. Centers for Disease Control and Prevention. Self-reported concern about food security associated with obesity. Washington, 19951999. MMWR Morb Mortal Wkly Rep. 2003;52(35):840-842.

37. Olson C. The Relationship between Hunger, Food Insecurity, and Obesity. http://www.frac.org/pdf/proceedings05.pdf. Accessed January 16, 2006.

38. James SA, Fowler-Brown A, Raghunathan TE, Van Hoewyk J. Lifecourse socioeconomic position and obesity in African American women: the Pitt County Study. Am J Public Health. 2006;96(3):554-560.

39. Bindon JR, Baker PT. Bergmann's rule and the thrifty genotype. Am J Phys Anthropol. 1997;104(2):201-210.

40. Lev-Ran A. Human obesity: an evolutionary approach to understanding our bulging waistline. Diabetes Metab Res Rev. 2001;17(5):347-362.

41. Cameron AJ, Welborn TA, Zimmet PZ, et al. Overweight and obesity in Australia: the 1999-2000 Australian Diabetes, Obesity and Lifestyle Study (AusDiab). Med J Aust. 2003;178(9):427-432.

42. McDermott R. Ethics, epidemiology and the thrifty gene: biologica determinism as a health hazard. Soc Sci Med. 1998;47(9):1189-1195.
43. Gentles $D$, Metcalf $P$, Dyall L, et al. Metabolic syndrome prevalence in a multicultural population in Auckland, New Zealand. N Z Med J. 2007;120(1248):U2399.

44. Riddell T, Jackson R, Wells S, Braoad J, Bannink L. Assessing Maori/ non-Maori differences in cardiovascular disease risk and risk management in routine primary care practice using web-based clinical decision support: (PREDICT CVD-2). N Z Med J. 2007;120(1250):U2445.

45. Zimmet PZ, McCarty DJ, de Courten MP. The global epidemiology of non-insulin-dependent diabetes mellitus and the metabolic syndrome. J Diabetes Complications. 1997;11(2):60-68.

46. Diamond J. The double puzzle of diabetes. Nature. 2003;423(6940): 599-602.

47. Bray GA. The epidemic of obesity and changes in food intake: the Fluoride Hypothesis. Physiol Behav. 2004;82(1):115-121.

48. Drewnowski A, Popkin BM. The nutrition transition: new trends in the global diet. Nutr Rev. 1997;55(2):31-43.

49. Benjelloun S. Nutrition transition in Morocco. Public Health Nutr. 2002;5(1A):135-140.

50. Popkin BM. The nutrition transition and its health implications in lower-income countries. Public Health Nutr. 1998;1(1):5-21.

51. Heart Outcomes Prevention Evaluation Study Investigators. Effects of ramipril on cardiovascular and microvascular outcomes in people with diabetes mellitus: results of the HOPE study and MICRO-HOPE substudy. Lancet. 2000;355(9200):253-259.

52. Lopez RP, Hynes HP. Obesity, physical activity, and the urban environment: public health research needs. Environ Health. 2006;5:25.

53. Leyden KM. Social capital and the built environment: the importance of walkable neighborhoods. Am J Public Health. 2003;93(9):1546-1551.

54. Cairney J, Ostbye T. Time since immigration and excess body weight. Canadian Journal of Public Health. Revue Canadienne de Sante Publique. 1999;90(2):120-124.

55. Goel MS, McCarthy EP, Phillips RS, Wee CC. Obesity among US immigrant subgroups by duration of residence. JAMA. 2004;292(23):2860-2867.

56. Landman J, Cruickshank JK. A review of ethnicity, health and nutrition-related diseases in relation to migration in the United Kingdom. Public Health Nutr. 2001;4(2B):647-657.

57. Sobal J, Stunkard AJ. Socioeconomic status and obesity: A review of the literature. Psychol Bull. 1989;105(2):260-275.

58. Gremillion H. The cultural politics of body size. Annu Rev Anthropol. 2005;34:13-32.

59. Nullis C. Africa faces growing obesity problem. November 29 2006; http://www.breitbart.com/article.php?id=D8LNOP6G1Eshow_ article=1. Accessed March 27, 2007.

60. Kruger HS, Venter CS, Vorster HH, Margetts BM. Physical inactivity is the major determinant of obesity in black women in the North West Province, South Africa: the THUSA study. Transition and Health During Urbanisation of South Africa. Nutrition. 2002;18(5):422-427.

61. Lynch E, Liu K, Spring B, Hankinson A, Wei GS, Greenland P. Association of ethnicity and socioeconomic status with judgments of body size: The Coronary Artery Risk Development in Young Adults (CARDIA) Study. Am J Epidemiol. 2007;165(9):1055-1062.

62. Bennett GG, Wolin KY. Satisfied or unaware? Racial differences in perceived weight status. Int J Behav Nutr Phys Act. 2006;3:40.

63. Juarbe TC. Cardiovascular disease-related diet and exercise experiences of immigrant Mexican women. West J Nurs Res. 1998;20(6):765-782.

64. Davidson M, Knafl KA. Dimensional analysis of the concept of obesity. J Adv Nurs. 2006;54(3):342-350.

65. Becker DM, Yanek LR, Koffman DM, Bronner YC. Body image preferences among urban African Americans and whites from low income communities. Ethn Dis. 1999;9(3):377-386. 
66. Bailey EJ. Food Choice and Obesity in Black America: Creating a New Cultural Diet. New York, NY: Praeger; 2006.

67. Kumanyika S. Obesity, health disparities, and prevention paradigms: hard questions and hard choices. Prev Chronic Dis. 2005;2(4)A02. http://www.cdc.gov/pcd/issues/2005/oct/05_0025.htm.

68. Pollan M. You are what you grow. NY Times. April 22, 2007; http:// www.nytimes.com/2007/04/22/magazine/22wwlnlede.t.html?page wanted $=2 \varepsilon$ ei $=5124 \varepsilon$ en $=56 \mathrm{~d} 0833 \mathrm{dcf38897} \mathrm{c}$ ex $=1335067200 \varepsilon$ partner=permalinkEexprod = permalink. Accessed May 2, 2007.

69. Pollan M. The Omnivore's Dilemma: A Natural History of Four Meals. New York, NY: Penguin Press; 2006.

70. Qvortrup M. Globalisation and obesity. Obes Pract. 2005;1(2):10-12.

71. Gordon-Larsen P, Harris KM, Ward DS, Popkin BM. National Longitudinal Study of Adolescent H. Acculturation and overweightrelated behaviors among Hispanic immigrants to the US: the National Longitudinal Study of Adolescent Health. Soc Sci Med. 2003;57(11):2023-2034.

72. Prentice AM. The emerging epidemic of obesity in developing countries. Int J Epidemiol. 2006;35(1):93-99.

73. Tartamella L, Herscher E, Woolston C. Generation Extra Large: Rescuing Our Children From the Epidemic of Obesity. New York, NY: Basic Books; 2004

74. WHO/FAO. Diet, Nutrition and the Prevention of Chronic Diseases. WHO Technical Report Series 916. Geneva: WHO; 2003. WHO Technical Report Series 916

75. Dyer O. US government rejects WHO's attempts to improve diet. BMJ. 2004;328(7433):185.

76. Briscoe AC. Letter to Gro Harlem Brundtland, Director General of WHO. December 6, 2005:http://www.commercialalert.org/sugarthreat.pdf.

77. Brownell KD, Horgen KB. Food Fight. New York, NY: McGraw-Hill; 2004.

78. Wagner EH. Chronic disease management: what will it take to improve care for chronic illness? Eff Clin Pract. 1998;1(1):2-4.

79. Elliott K. Childhood Obesity Chronic Care Model. March 31, 2006; http://www.azdhs.gov/phs/oncdps/opp/pdf/childhood_obesity_ model\%20.pdf. Accessed July 14, 2007.
80. Siminerio LM, Piatt GA, Emerson S, et al. Deploying the chronic care model to implement and sustain diabetes self-management training programs. Diabetes Educ. 2006;32(2):253-260.

81. Landon BE, Hicks LS, O'Malley AJ, et al. Improving the management of chronic disease at community health centers. $N$ Engl J Med. 2007;356(9):921-934.

82. Sterman JD. Learning from evidence in a complex world. Am J Public Health. 2006;96(3):505-514

83. Milstein B. Centers for Disease Control and Prevention. Syndemics Prevention Network. Syndemic Thinking and Simulation Studies in Public Health Work: Methodological Consideration in Interdisciplinary Health Behaviors/Social Science Research. NIH Roadmap Methodology and Technology Summit. Bethesda, MD; 2006. http:// nihroadmap.nih.gov/interdisciplinary/summit0806/pps/Milstein. pps. Accessed July 4, 2007.

84. Milstein B. Centers for Disease Control and Prevention. Syndemics Prevention Network. Modeling the Population Health Dynamics of Diabetes $\&$ Obesity. Texas Public Health Association. Galveston, TX. February 26, 2007. http://www.dshs.state.tx.us/phn/pdf/Modeling\%20 Diabesity\%20Dynamics\%20(Milstein).pdf. Accessed July 14, 2007.

85. Jones AP, Homer JB, Murphy DL, Essien JDK, Milstein B, Seville DA. Understanding diabetes population dynamics through simulation modeling and experimentation. Am J Public Health. 2006;96(3):488-494.

86. Homer JB, Hirsch GB. System dynamics modeling for public health: background and opportunities. Am J Public Health 2006;96(3):452-458

87. Candib LM. How turning a QI project into "research" almost sank a great program: personal reflections of a community health center physician. Hastings Cent Rep. 2007;37(1):26-30.

88. Woodward-Lopez G, Flores GR. Obesity in Latino Communities: Prevention, Principles, and Action. December, 2006; http://www. cnr.berkeley.edu/cwh/PDFs/Obesity_in_Latino_Communities.pdf. Accessed March 28, 2007.

89. Verheijden MW, Kok FJ. Public health impact of communitybased nutrition and life-style interventions. Eur J Clin Nutr. 2005;59(Suppl 1):S66-S76

90. Summerbell CD, Waters E, Edmunds LD, Kelly S, Brown T, Campbell $\mathrm{KJ}$. Interventions for preventing obesity in children. Cochrane Database of Systematic Reviews. 2005;3:CD001871. 